Physical fitness programmes must be carefully supervised, and a preliminary medical examination is essential in cases where vigorous exertion (often to exhaustion) is undertaken by

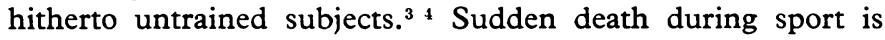
well documented. ${ }^{22} \mathrm{~A}$ family history of early heart attacks and antecedent symptoms of chest pain must be taken seriously.

Provided that such safeguards are observed, this study has shown that a healthy young man will achieve significant improvement in absolute strength $(29-30 \%)$ and in stamina or cardiopulmonary reserve $(15-25 \%)$ within two weeks when training for 20 minutes a day. Prolonged training can improve a subject's physical fitness index from 80 to 120 over several months (Zatopek achieved an index of 172 when tested using a Harvard step test of 20 inches $^{7}$ ); but just as fitness can be achieved quickly, once training stops regression occurs quickly. Five weeks after cessation of an efficient training course, enduranceproduced electrocardiogram changes have already disappeared. ${ }^{13}$

I thank colleagues of the Queensland University Regiment, and the 21 Psychology Unit, Royal Australian Army, for their help, and Brigadier R I Harrison for support.

Requests for reprints should be sent to: Dr John Pearn, Department of Child Health, Royal Children's Hospital, Herston, Brisbane, Australia 4029.

\section{References}

1 Rasch PJ, Wilson ID. The correlation of selected laboratory tests of physical fitness with military endurance. Milit Med $1964 ; 129: 256-8$.

2 Buxaum R, O'Connor R. Fitness trials. $N$ Engl f Med 1977;296:690-1.

3 Bannister R. Sport, physical recreation and the national health. Br Med $\mathscr{f}$ $1972 ; 4: 711-5$

4 Adamson GT. Training methods. Physiotherapy 1972;58:207-10.
${ }^{5}$ Brunner BC. Personality and motivating factors influencing adult participation in vigorous physical activity. Res $Q \mathrm{Am}$ Assoc Health Phys Educ 1969;40:464-9.

${ }^{6}$ Campbell DE. Relationship between scores on the Wear attitude inventory and selected physical fitness scores. Res $Q \mathrm{Am}$ Assoc Health Phys Educ $1969 ; 40: 470-4$

${ }^{7}$ Morgan RE, Adamson GT. Circuit training. 2nd ed. London: G Bell and Sons, $1961: 65-91$

8 Rasch PJ, Otott GE, Brown M, Wilson ID, Norton RJ. Evaluation of a new combat conditioning course. Milit Med 1966;131:130-6.

${ }^{9}$ Martin BJ, Robinson S, Wiegman DL, Aulick LH. Effects of warm-up on metabolic responses to strenuous exercise. Med Sci Sports 1975;7: 146-9.

${ }^{10}$ Malarecki I. Investigation on physiological justification of so-called "warming-up." Acta Physiol Scand 1954;5:543-6.

11 Massey BH, Johnson WR, Kramer GF. Effect of warm-up exercise upon muscular performance using hypnosis to control the psychological variable. Res $O \mathrm{Am}$ Assoc Health Phys Educ 1961 ;32:63-71.

12 Marcano BA, Moss AJ. Spurious heart disease in athletic children. f Pediatr 1968;72:664-8.

13 Fardy PS. Effects of soccer training and detraining upon selected cardiac and metabolic measures. Res $Q$ Am Assoc Health Phys Educ 1969;40: 502-8.

14 Huxley AF. Muscular contraction. F Physiol $1974 ; 243: 1-43$

15 Cumming GR, Goulding D, Baggley G. Failure of school physical education to improve cardiorespiratory fitness. Can Med Assoc $\mathcal{F}$ $1969 ; 101: 69-73$.

16 Abraham WM, Craig AB. Tension decline during isometric contractions without visual cues. Med Sci Sports 1975;7:99-104.

17 Todd FE. Democratic methodology in physical education. Sociometry $1951 ; 14: 203-9$.

18 Bassler TJ. Previous health and longevity of male athletes. Lancet 1972; ii:711-2.

19 Polednak AP. Previous health and longevity of male athletes. Lancet $1972 ; \mathrm{ii}: 711$.

${ }^{20}$ War Office (UK). A guide to the organisation and control of physical training. London HMSO, 1963 (WO Code No 9853), 5.

${ }^{21}$ Tharp GD, Carson WH. Emotionality changes in rats following chronic exercise. Med Sci Sports $1975 ; 7: 123-6$.

22 Opie LH. Sudden death and sport. Lancet $1975 ; \mathrm{i}: 263-6$.

(Accepted 15 October 1980)

\title{
Grey-scale ultrasonography and percutaneous transhepatic cholangiography in biliary tract disease
}

\author{
S R WILD, J G CRUIKSHANK, G M FRASER, W A COPLAND, D C GRIEVE
}

\section{Summary and conclusions}

Fifty-one patients with suspected obstructive jaundice and 14 without jaundice in whom disease of the biliary tract was suspected but infusion cholangiography had been unhelpful were examined by grey-scale ultrasonography and percutaneous transhepatic cholangiography and the findings analysed retrospectively. Grey-scale ultrasonography distinguished between obstructive and hepatocellular jaundice in 35 out of 46 patients $(76 \%)$ and indicated the site of the obstruction in $27(58 \%)$ and the cause of the obstruction in $13(28 \%)$. Percutaneous transhepatic cholangiography distinguished between obstructive and hepatocellular jaundice in 42 of the patients $(91 \%)$ and indicated the site of the obstruction in $42(91 \%)$ and the cause in $29(63 \%)$. In the 14 patients without jaundice percutaneous transhepatic cholangio-

\footnotetext{
Department of Radiodiagnosis, Western General Hospital, Edinburgh EH4 2XU

S R WILD, MB, FRCR, consultant radiologist

J G CRUIKSHANK, FRCP, FRCR, consultant radiologist

G M FRASER, MB, FRCR, consultant radiologist

W A COPLAND, FRCSE, FRCR, consultant radiologist

D C GRIEVE, MB, FRCR, consultant radiologist
}

graphy showed bile-duct stones in one and ampullary stenosis in three.

It is concluded that grey-scale ultrasonography and percutaneous transhepatic cholangiography are complementary examinations and that ultrasonography should always be undertaken first as it is a non-invasive procedure that may provide the surgeon with all the diagnostic information he requires. Percutaneous transhepatic cholangiography should be performed when grey-scale ultrasonography has shown dilated bile ducts but failed to provide adequate diagnostic information. Cholangiography is also required when preoperative percutaneous drainage of the bile duct is contemplated. In those patients in whom grey-scale ultrasonography shows non-dilated ducts endoscopic retrograde cholangiopancreatography is probably the contrast examination of choice.

\section{Introduction}

Percutaneous transhepatic cholangiography is a reliable method of differentiating obstructive from hepatocellular jaundice with an accuracy of between $96 \%$ and $100 \% .^{12}$ In one series the technique detected the cause of the obstruction in $71 \%$ of cases, $^{3}$ and in another was claimed to be $100 \%$ accurate in 
establishing both the site and cause of the obstruction. ${ }^{4}$ Greyscale ultrasonography is also a reliable method of distinguishing obstructive from hepatocellular jaundice, with an accuracy of between $72 \%$ and $96 \% \cdot{ }^{14-7}$ Figures varying between $7 \%$ and $81 \%$, however, are quoted for its accuracy in determining the cause of the obstruction. ${ }^{14589}$

Gold $e t$ al ${ }^{4}$ stated that they had found percutaneous transhepatic cholangiography to be the more useful procedure in elucidating jaundice of obscure aetiology, whereas Koenigsberg et $a l^{1}$ concluded that sonography had become the imaging method of choice in establishing the cause of obstruction in patients with surgical jaundice. Smith et al ${ }^{10}$ suggested that endoscopic retrograde cholangiopancreatography may be useful in patients with chronic pancreatitis in detecting biliary calculi even when results of oral cholecystography and intravenous cholangiography are normal. More recently, Bull et al ${ }^{11}$ expressed two consultant radiologists with wide experience of ultrasonography, and percutaneous transhepatic cholangiography by three consultant radiologists, the technique used being similar to that described previously. ${ }^{12}$

The final diagnosis was reached in most cases at operation or post mortem and in the remainder by liver biopsy or during the clinical course of the disease. Complications occurring after percutaneous transhepatic cholangiography were recorded.

\section{Results}

Extraheptic obstruction was confirmed in 46 of the 51 patients with jaundice (table 1).

Sixteen patients had carcinoma of the head of the pancreas: the site of the obstruction was correctly assessed by grey-scale ultrasonography in 13 cases $(81 \%)$ and by percutaneous transhepatic cholangiography in $15(94 \%)$. Ultrasonography indicated the cause of

TABLE I-Accuracy of grey-scale ultrasonography (GSU) and percutaneous transhepatic cholangiography (PTC) in detecting dilated ducts and site and cause of obstruction in 46 patients with obstructive jaundice

\begin{tabular}{|c|c|c|c|c|c|c|c|}
\hline \multirow{2}{*}{ Final diagnosis } & \multirow{2}{*}{$\begin{array}{c}\text { No of } \\
\text { patients }\end{array}$} & \multicolumn{2}{|c|}{ Dilated ducts } & \multicolumn{2}{|c|}{ Site of obstruction } & \multicolumn{2}{|c|}{ Cause of obstruction } \\
\hline & & GSU & PTC & GSU & PTC & GSU & PTC \\
\hline $\begin{array}{l}\text { Carcinoma of head of pancreas } \\
\text { Carcinoma of bile ducts or ampulla } \\
\text { Secondary tumour in porta hepatis or liver } \\
\text { Stones in common bile duct } \\
\text { Benign stricture of common bile duct } \\
\text { Inflammatory mass in head of pancreas }\end{array}$ & $\begin{array}{r}16 \\
7 \\
7 \\
10 \\
5 \\
1\end{array}$ & $\begin{array}{r}16 \\
3 \\
5 \\
8 \\
3\end{array}$ & $\begin{array}{c}15^{*} \\
7 \\
7 \\
7 \dagger \\
5 \\
1\end{array}$ & $\begin{array}{r}13 \\
3 \\
5 \\
4 \\
2\end{array}$ & $\begin{array}{r}15 \\
7 \\
7 \\
7 \\
5 \\
1\end{array}$ & $\begin{array}{l}8 \\
4 \\
1\end{array}$ & $\begin{array}{r}12 \\
1 \\
5 \\
7 \\
4\end{array}$ \\
\hline Total (\%) & 46 & $35(76 \%)$ & $42(91 \%)$ & $27(58 \%)$ & $42(91 \%)$ & $13(28 \%)$ & $29(63 \%)$ \\
\hline
\end{tabular}

Percutaneous transhepatic cholangiography failed in * one patient; $\uparrow$ three patients.

TABLE II-Results of grey-scale ultrasonography (GSU) and percutaneous transhepatic cholangiography (PTC) in 14 patients in whom infusion cholangiography failed or gave equivocal results

\begin{tabular}{|c|c|c|c|}
\hline $\begin{array}{l}\text { Case } \\
\text { No }\end{array}$ & GSU & PTC & Final diagnosis and how established \\
\hline $\begin{array}{l}1 \\
2 \\
3 \\
4 \\
5 \\
6 \\
7 \\
8\end{array}$ & $\begin{array}{l}\text { Failed (gas and scars) } \\
\text { Normal } \\
\text { Normal } \\
\text { Normal } \\
\text { Normal } \\
\text { Normal } \\
\text { Normal } \\
\text { Failed (scars) }\end{array}$ & $\begin{array}{l}\quad \text { Patients with pain after chol } \\
\text { Normal } \\
\text { Failed } \\
\text { Stone in common bile duct } \\
\text { Failed } \\
\text { Ampullary stenosis } \\
\text { Failed } \\
\text { Ampullary stenosis } \\
\text { Failed }\end{array}$ & $\begin{array}{l}\text { lecystectomy } \\
\text { Normal biliary tree; by PTC and ERGP } \\
\text { None } \\
\text { Stone in common bile duct; at operation } \\
\text { Normal biliary tree; by operative cholangiography } \\
\text { Ampullary stenosis; by ERCP and at operation } \\
\text { Stone in common bile duct; at operation } \\
\text { Ampullary stenosis; at operation } \\
\text { Normal biliary tree; by ERCP }\end{array}$ \\
\hline $\begin{array}{r}9 \\
10 \\
11 \\
12\end{array}$ & $\begin{array}{l}\text { Failed } \\
\text { Normal } \\
\text { Normal } \\
\text { Normal }\end{array}$ & $\begin{array}{l}\text { Failed Patients with chronic p } \\
\text { Normal } \\
\text { Failed } \\
\text { Stenosis of common bile duct }\end{array}$ & $\begin{array}{l}\text { Normal biliary tree; operative cholangiography } \\
\text { Normal biliary tree; by PTC } \\
\text { Normal biliary tree; by postmortem examination } \\
\text { Stenosis of common bile duct; at operation }\end{array}$ \\
\hline $\begin{array}{l}13 \\
14\end{array}$ & $\begin{array}{l}\text { Normal } \\
\text { Normal }\end{array}$ & $\begin{array}{l}\text { Patients with undiagnosed at } \\
\text { Failed } \\
\text { Failed }\end{array}$ & $\begin{array}{l}\text { dominal pain } \\
\text { Normal biliary tree; operative cholangiography } \\
\text { Normal biliary tree; operative cholangiography }\end{array}$ \\
\hline
\end{tabular}

ERCP = Endoscopic retrograde cholangiopancreatography.

the view that endoscopic retrograde cholangiopancreatography is usually unhelpful in diagnosing unexplained abdominal pain.

Such widely differing figures and divergent opinions can only confuse the clinician. We therefore describe in a retrospective study our experience of the relative values of percutaneous transhepatic cholangiography and grey-scale ultrasonography in two groups of patients-namely, those with suspected obstructive jaundice and those with suspected biliary disease in whom infusion cholangiography had either failed or given equivocal results.

\section{Methods}

Fifty-one patients with clinical and biochemical evidence of obstructive jaundice and 14 patients without jaundice in whom disease of the biliary tract was suspected clinically but infusion cholangiography had been unhelpful were examined by both grey-scale ultrasonography and percutaneous transhepatic cholangiography. Several patients, mainly referrals from other hospitals, who were examined by only grey-scale ultrasonography were omitted from this study. In most cases both examinations were carried out on the same day, and in all but eight cases the two examinations were performed within one week of each other. Grey-scale ultrasonography was performed by the obstruction in eight cases. On cholangiography a confident diagnosis was made in 12 cases $(75 \%)$, the cholangiogram showing a sharply cut off rat-tail stricture or characteristic downward-pointing convexity at the lower end of the common bile duct. ${ }^{3}$

Percutaneous transhepatic cholangiography accurately detected the site of the obstruction in all seven patients with carcinoma of the bile ducts or ampulla, but neither grey-scale ultrasonography nor percutaneous transhepatic cholangiography accurately determined the cause of the obstruction (0/7 and $1 / 7$ cases respectively). This is understandable with ultrasonography, since the tumour is usually too small to be detected by this method and the area is often obscured by bowel gas. On cholangiography we could not give a definitive diagnosis and offered various differential diagnoses including stricture, tumour, stone, sclerosing cholangitis, and inflammatory mass.

Both grey-scale ultrasonography and percutaneous transhepatic cholangiography were considerably more accurate in determining the cause of the obstruction when this was due to secondary tumour in the region of the porta hepatis or in the liver (4/7 and 5/7 cases respectively). In the case of ultrasonography this was because the area is more accessible and the tumour usually larger. On cholangiography the lobulated indentation on the bile ducts is characteristic.

Ten patients had stones in the common bile duct. In eight of these dilated ducts were seen on ultrasonography but in only one was the stone itself visible. This poor detection rate was due largely to difficulty in visualising the lower end of the common bile duct because 
of gas in the duodenum and colon. In three of the ten patients percutaneous transhepatic cholangiography failed as the ducts were either not dilated or only marginally dilated. The characteristic upward-facing convexity ${ }^{3}$ was evident in the seven cases in which cholangiography was successful, and a confident diagnosis was made in each case.

Five patients had benign strictures of the common bile duct. Grey-scale ultrasonography showed dilated ducts in three but failed to show the cause. The cause of the obstruction was accurately determined by percutaneous transhepatic cholangiography in four cases, since smooth tapering of the common bile duct at the site of the stricture was evident.

Five patients had non-obstructive jaundice. Infective hepatitis was finally diagnosed in two, portal cirrhosis in two, and cholelithiasis (without evidence of choledocholithiasis at operation) in one. Greyscale ultrasonography showed a normal biliary tract and pancreas in three of these five patients and correctly detected the gall-bladder stones; in one patient, however, it incorrectly indicated a mass in the head of the pancreas, which in retrospect was probably caused by the presence of food and fluid in the duodenum. Percutaneous transhepatic cholangiography showed a normal biliary system in two cases but failed in the three others. Failure of contrast to enter a duct on cholangiography together with evidence of non-dilated ducts on ultrasonography suggests that the jaundice is non-obstructive.

Table II shows the findings in the 14 patients in whom infusion cholangiography failed or gave equivocal results. Grey-scale ultrasonography showed no abnormality in the biliary tract or pancreas; the technique failed to detect stones in the common bile duct, which were eventually diagnosed in two patients. Percutaneous transhepatic cholangiography was successful in only six cases $(43 \%)$ but detected one of the two cases with stones in the common bile duct and all three cases with stenosis of the ampulla or common bile duct.

Complications occurred in six of the 65 patients $(9 \%)$ after percutaneous transhepatic cholangiography. Two cases of cholangitis and septicaemia and one of transient fever were successfully managed medically. In two patients an asymptomatic bile leak was found at operation. A pneumothorax occurred in a patient with emphysema, who recovered uneventfully after insertion of an intercostal drain.

\section{Discussion}

In this series obstructive jaundice was diagnosed by grey-scale ultrasonography in 35 out of 46 patients $(76 \%)$ and by percutaneous transhepatic cholangiography in 42 (91\%). Cholangiography failed in four cases, but in two of these ultrasonography showed dilated ducts. The combined accuracy of the two examinations was therefore $96 \%$.

In patients with obstructive jaundice due to tumour it is particularly important for the surgeon to know the site of the obstruction. If it is below the origin of the cystic duct he can if necessary perform palliative cholecystenterostomy, whereas if it is above the origin of the cystic duct a more complex drainage procedure will be required. We therefore paid particular attention to the presence or absence of dilated intrahepatic ducts or a dilated gall bladder. If this was assessed accurately the site of the obstruction was deemed to have been correctly determined. Similarly, when using percutaneous transhepatic cholangiography we sought to show whether the obstruction was above or below the origin of the cystic duct. Preoperative knowledge of the cause of the obstruction will usually enable the surgeon to plan the most appropriate treatment.

In the 16 patients with carcinoma of the head of the pancreas the site of the obstruction was correctly assessed by grey-scale ultrasonography in 13 cases $(81 \%)$ and by percutaneous transhepatic cholangiography in $15(94 \%)$. The cause of the obstruction was shown in eight patients on ultrasonography. This compares with an accuracy of between $33 \%$ and $97 \%$ in other series. ${ }^{46-9}$ Dilated ducts were seen on ultrasonography in eight of the 10 patients with stones in the common bile duct, but in only one patient was the stone itself visible. This accuracy of $10 \%$ is lower than the $33-82 \%$ reported elsewhere. ${ }^{148} 9$ The relatively poor success rate of percutaneous transhepatic cholangiography in patients with dilated ducts was partly because to minimise the radiation dose to radiologists' fingers we now tend to limit the prolonged screening time that is some- times required in these patients to achieve successful cholangiograms. ${ }^{13}$ Moreover, we believe that these patients may be more satisfactorily examined by endoscopic retrograde cholangiopancreatography when this technique is readily available.

The incidence of complications with percutaneous transhepatic cholangiography $(9 \%)$ is the same as that reported by us. ${ }^{12}$ No deaths occurred and no patients required emergency operations, but the technique does carry a recognisable morbidity. Although a diagnosis was achieved by percutaneous transhepatic cholangiography in only six of the 14 patients in whom infusion cholangiography failed or gave equivocal results, it did identify one of the two patients with stones in the common bile duct and all three patients with stenosis of the ampulla or bile duct. Hence we disagree with Bull et al, ${ }^{11}$ who said that contrast radiology of the biliary tract, whether by percutaneous transhepatic cholangiography or endoscopic retrograde cholangiopancreatography, is usually unhelpful in patients presenting with unexplained pain.

In this series grey-scale ultrasonography distinguished between obstructive and hepatocellular jaundice in $76 \%$ of patients and showed the site of the obstruction in $58 \%$ and the cause of the obstruction in $28 \%$. As it is a simple, non-invasive technique our policy now is to perform grey-scale ultrasonography first in patients with suspected obstructive jaundice. In cases in which both the site and cause of the obstruction have been definitively diagnosed the only reason for proceeding to percutaneous transhepatic cholangiography is to provide drainage of an obstructed system. Ultrasonography may also give information on the cause of jaundice in patients with mixed disease, such as liver metastases and obstructing nodes in the porta hepatis, and its place in locating a pancreatic mass before fine-needle aspiration for cytology is now firmly established. ${ }^{14}$

We cannot agree with those who would suggest that one or other technique is the procedure of choice. We believe the two examinations to be complementary; close liaison between the referring doctor and the radiologists performing the two examinations is essential so that the clinical decision giving the maximum benefit to each patient is made.

\section{References}

${ }^{1}$ Koenigsberg M, Wiener SN, Walzer A. The accuracy of sonography in the differential diagnosis of obstructive jaundice: a comparison with cholangiography. Radiology 1979;133:157-65.

2 Goldstein LI, Sample WF, Kadell BM, Weiner M. Gray-scale ultrasonography and thin-needle cholangiography: evaluation in the jaundiced patient. F $A M A$ 1977;238:1041-4

3 Owen JP. Analysis of the signs of common bile duct obstruction at percutaneous transhepatic cholangiography. Clin Radiol 1980;31:271-6.

4 Gold RP, Casarella WJ, Stern G, Seaman WB. Transhepatic cholangiography: the radiological method of choice in suspected obstructive jaundice. Radiology 1979;133:39-44.

5 Morris AI, Fawcitt RA, Wood R, Forbes WSC, Isherwood I, Marsh MN. Computed tomography, ultrasound, and cholestatic jaundice. Gut 1978 ; $19: 685-8$.

6 Vicary FR, Cusick G, Shirley IM, Blackwell RJ. Ultrasound and jaundice. Gut 1977;18:161-4.

${ }^{7}$ Hadidi A. Distinction between obstructive and non obstructive jaundice by sonography. Clin Radiol 1980;31:181-7.

${ }^{8}$ Vallon AG, Lees WR, Cotton PB. Grey-scale ultrasonography in cholestatic jaundice. Gut 1979;20:51-4.

${ }^{9}$ Dewbury KC, Joseph AEA, Hayes S, Murray C. Ultrasound in the evaluation and diagnosis of jaundice. Br $\mathcal{F}$ Radiol 1979;52:276-80.

10 Smith R, Williams R, Cotton PB. Gallstone pancreatitis with normal biliary radiology. Br $\mathcal{F}$ Surg $1976 ; 63: 861-3$.

${ }^{11}$ Bull J, Keeling PWN, Thompson RPH. Endoscopic retrograde cholangio pancreatography for unexplained upper abdominal pain. $\mathrm{Br} \mathrm{Med} f$ $1980 ; 280: 764$.

12 Fraser GM, Cruikshank JG, Sumerling MD, Buist TAS. Percutaneous transhepatic cholangiography with the chiba needle. Clin Radiol 1978 ; 29:101-12.

13 Cruikshank JG, Fraser GM, Law J. Finger doses received by radiologists during chiba needle percutaneous cholangiography. $B r F$ Radiol 1980 ; $53: 584-5$.

14 Holm HH, Als O, Gammelgaard J. Percutaneous aspiration and biopsy procedures under ultrasound visualization. In: Taylor $\mathrm{KJW}$, ed. Diagnostic ultrasound in gastrointestinal disease. New York, Edinburgh, and London: Churchill Livingstone, 1979:137-49.

(Accepted 9 October 1980) 